\title{
Perspectivas teóricas da corrupção no campo da administração pública brasileira: características, limites e alternativas
}

\author{
Temístocles Murilo Oliveira Júnior \\ Universidade Federal do Rio de Janeiro (UFRJ) \\ Frederico José Lustosa da Costa \\ Universidade Federal Fluminense (UFF)
}

Arnaldo Paulo Mendes

Universidade Estácio de Sá

Este trabalho traça um panorama das principais perspectivas teóricas que orientam a análise da corrupção no campo da administração pública brasileira, investiga seus limites e busca alternativas que os transponham. Tais perspectivas relacionam-se às vertentes das teorias de modernização e da nova economia institucional, que se centram, respectivamente, nos conceitos de patrimonialismo e de rent-seeking para análise da corrupção. A literatura crítica indica que essas vertentes apresentam limites por desconsiderarem fatores políticos, econômicos e culturais que seriam fundamentais para a compreensão de tal fenômeno em diferentes sociedades ou mesmo organizações. Como resultado, seus modelos de análise não articulariam todas as variáveis de nível macro, meso e micro relacionadas ao conjunto de causas relevantes da corrupção. Buscando-se alternativas, analisou-se a teoria da ação social de Bourdieu, centrada no conceito de habitus. Apesar de se ter verificado que tal teoria poderia transpor os limites indicados, não foram encontradas experiências de sua aplicação na análise de casos concretos.

Palavras-chave: corrupção, administração pública, modernização administrativa, patrimonialismo

[Artigo recebido em 7 de maio de 2015. Aprovado em 17 de março de 2016.] 
Perspectivas teóricas de corrupción en el campo de la administración pública brasileña: rasgos, límites y alternativas

Este trabajo presenta una visión general de las principales perspectivas que guían el análisis de la corrupción en el ámbito de la administración pública en Brasil, estudia sus límites y busca alternativas. Estas perspectivas están relacionados con los enfoques de la modernización y la nueva economía institucional, que se centran en los conceptos de patrimonialismo y el rent-seeking para el análisis de la corrupción. La literatura que critica estos enfoques indica que tienen límites porque ignoran los factores políticos, económicos y culturales que son fundamentales para la comprensión del fenómeno de la corrupción en las diferentes sociedades $u$ organizaciones. Por lo tanto, los esquemas de análisis basados en estas perspectivas no serían capaces de articular todas las variables macro, meso y micro-nivel que representan las causas relevantes de corrupción. En busca de alternativas, este trabajo analiza la teoría de la acción social, que se centra en el concepto de habitus de Bourdieu. Aunque se observó que esta teoría puede superar los límites indicados, no se encontró experiencias de su aplicación a estudiar casos empíricos de corrupción.

Palabras clave: corrupción, administración pública, modernización administrativa, patrimonialismo

Theoretical perspectives of corruption in the field of Brazilian public administration: characteristics, limits and alternatives

This work presents an overview of the main perspectives that guiding the analysis of corruption in the field of public administration in Brazil. The work also studies these perspectives limits and looks for alternatives. The mentioned views are related to the approaches of modernization and new institutional economics, which are focused on the concepts of patrimonialism and rent-seeking in the analysis of corruption. The literature that criticizes these approaches indicates they have limits because they ignore political, economic and cultural factors which are fundamental to understanding the phenomenon of corruption in different societies or organizations. Thus, the analysis schemes based on these perspectives would not be able to articulate all macro, meso and micro-level variables that represent the relevant causes of corruption. Seeking alternatives, this work analyzed the Bourdieu's theory of social action, which is focused on the concept of habitus. Although it was observed that this theory can overcome the indicated limits, it was not found experiences of its application to study empirical cases of corruption.

Keywords: corruption, public administration, administrative modernization, patrimonialism 


\section{Introdução}

Este trabalho examina as características das principais perspectivas teóricas que orientam a análise do fenômeno da corrupção no campo da administração pública brasileira, investiga seus limites e busca alternativas que os transponham.

No século 20, as perspectivas sobre a corrupção foram organizadas em torno de duas principais agendas de pesquisa (FILGUEIRAS, 2008b). A primeira, predominante até os anos 1990, baseia-se na vertente da modernização. Essa, no caso do estudo da corrupção no Brasil, centra-se no conceito do patrimonialismo (SouZA, 2008; FILGUEIRAS, 2009). A segunda, hegemônica a partir da ascensão do programa de reformas baseado na New Public Management, relaciona-se à vertente da nova economia institucional e tem o rent-seeking como principal conceito para o estudo da corrupção (FILgUeIRAS, 2008A; LUSTOSA DA COSTA, 2010; ROSE-ACKERMAN, 2010). Essas perspectivas marcam paradigmas sobre tal fenômeno e resultam da evolução do pensamento sobre ele, que, sendo histórico, vem se alterando no tempo em relação tanto aos sentidos que lhe são atribuídos quanto às ideias sobre seu enfrentamento (CARVALHO, 2008).

A importância do estudo de tais perspectivas reside em dois pontos. O primeiro se relaciona à malignidade emprestada à corrupção no Brasil e à consequente importância conferida à sua análise e combate. Segundo Bignotto (2011, p. 1516), duas pesquisas realizadas em 2008 e 2009 indicaram que a opinião pública brasileira "considera a corrupção uma das principais mazelas do país e a julga a responsável por muitos dos problemas que afligem nossa população". Mesmo sendo um fenômeno sobre o qual já existe grande debate, o caráter fugidio da ideia de corrupção e a tendência moralista das abordagens sobre suas causas, práticas e efeitos demandam a realização de estudos mais acurados, voltados à compreensão de sua extensão e profundidade (FILGUEIRAS, 2009; BIGNOTTO, 2011).

O segundo ponto é o de que há uma relação estreita entre a evolução do pensamento sobre a corrupção e as experiências de reforma experimentadas no Brasil. Analisados os estudos de Lustosa da Costa (2010) e Paula (2005), verificase que as duas mais significativas experiências, iniciadas nos anos 1930 e 1990, se embasaram em teorias relacionadas a tais perspectivas sobre a corrupção, acompanhando-as em sua predominância na história.

Em que pese haver, como apontam Graaf (2007) e Graaf, Maravić e Wagenaar (2010), outras perspectivas teóricas e um numeroso conjunto de autores com estudos representativos em relação àquelas em comento, a pesquisa bibliográfica que deu base a este trabalho restringiu-se ao escopo necessário ao seu objetivo. 
Limitou-se, assim, às vertentes destacadas, focando-se primariamente nas ideias dos autores mais influentes sobre o estudo da corrupção no campo da administração pública brasileira.

Dessa forma, o conjunto de obras selecionadas como fonte de pesquisa referente à primeira perspectiva ficou relacionado primariamente àquelas de Sérgio Buarque de Holanda e Raymundo Faoro, apontadas por Souza (2008) e Lustosa da Costa (2010) como clássicos da literatura sobre a vertente da modernização no Brasil e de sua aplicação para compreensão da corrupção. Sobre a segunda perspectiva, selecionaram-se os estudos de Robert Klitgaard, Susan Rose-Ackerman e Marcos Fernandes Gonçalves da Silva, apontados por Sacramento e Pinho (2009) como os autores mais referenciados em trabalhos acadêmicos sobre a corrupção a partir daquela vertente no campo da administração pública brasileira. Além das obras dos autores citados, utilizaram-se também os estudos críticos de outros que debatem as características e os limites de tais perspectivas.

Divide-se este trabalho em quatro seções. As duas primeiras trazem as características das vertentes em comento. A terceira apresenta o levantamento dos seus limites apontados pela literatura sobre o tema. Na última, analisa-se uma possível alternativa que superaria tais limites, a teoria da ação social de Bourdieu, destacando-se não terem sido encontradas experiências de sua aplicação para análise de casos concretos.

\section{A modernização}

A primeira grande perspectiva sobre a corrupção no século 20 , predominante até os anos 1990, aborda a corrupção a partir da perspectiva da modernização (FIlgueIRAS, 2008b). Essa baseia-se primariamente nos estudos de Max Weber relacionados aos tipos de dominação legítima, às formas de orientação da ação e aos conceitos de patrimonialismo, burocracia e estamento, partindo de uma epistemologia centrada na construção da compreensão dos fenômenos sociais a partir da concepção de modelos ideais.

Em pesquisa crítica acerca da perspectiva sobre a corrupção no Brasil a partir do pensamento de Weber, Souza (2008) indica que o patrimonialismo seria seu conceito central. Por ele, a corrupção seria resultante de arranjos institucionais pré-modernos, em que predominariam relações de dominação legitimadas pela tradição (arcaicas), em contraposição ao moderno, em que predominaria o tipo de legitimação ideal, orientada pelo paradigma racional-legal ocidental. Os estudos sobre a corrupção no Brasil a partir de tal perspectiva teriam como obras seminais 
Raízes do Brasil e Os donos do poder, de Sérgio Buarque de Holanda e Raymundo Faoro, respectivamente (SOUZA, 2008; LUSTOSA DA COSTA, 2010).

Holanda (1995) analisa o processo de formação da sociedade brasileira apontando a existência de tipos primitivos de organização social baseados na família patriarcal, indicando que o desenvolvimento das cidades e da máquina pública não poderia se dar sem a reprodução das falhas típicas de tal formação.

Não era fácil aos detentores das posições públicas de responsabilidade, formados por tal ambiente, compreenderem a distinção fundamental entre os domínios do privado e do público. Assim, eles se caracterizavam justamente pelo que separa o funcionário "patrimonial" do puro burocrata conforme a definição de Max Weber. Para o funcionário "patrimonial", a própria gestão política apresenta-se como assunto de seu interesse particular; as funções, os empregos e os benefícios que deles aufere relacionam-se a direitos pessoais do funcionário e não a interesses objetivos, como sucede no verdadeiro Estado burocrático, em que prevalecem a especialização das funções e o esforço para se assegurarem garantias jurídicas aos cidadãos (HOLANDA, 1995, p. 145-146).

Examinando qual seria o comportamento dos indivíduos no contexto resultante da formação da sociedade brasileira, Holanda (1995) cunhou a noção de "homem cordial". A cordialidade, traço definido do caráter brasileiro, representaria a maneira pela qual o indivíduo conseguiria manter sua supremacia sobre o social, mesmo porque a vida na modernidade exigiria determinadas regras às quais o comportamento do brasileiro não teria correspondência (SOUZA, 2008; FILGUEIRAS, 2009). Assim, mais do que polidez ou irracionalidade emotiva, a cordialidade visaria dar viabilidade a um comportamento que buscaria a afirmação dos interesses particulares do homem cordial sobre o interesse público.

Afastado da racionalidade pública típica da modernidade, o homem cordial se constituiria em elemento primário das relações sociais de um Brasil ainda arcaico, servindo de aporte teórico para explicação do comportamento dos indivíduos em um arranjo institucional em que o tipo de dominação legítima é tradicional. Assim, "o personalismo é representado pela prática social do homem cordial na esfera privada e pública [e] o patrimonialismo representaria o homem cordial como membro de um suposto 'estamento' estatal" (SouzA, 2008, p. 84).

Faoro (2000a, 2000b) apresenta a tese de que os diversos problemas enfrentados pelo Brasil, incluídos aí a corrupção, seriam resultantes da prevalência de um modelo institucional baseado no "capitalismo politicamente orientado". 
Esse tipo de capitalismo teria incorporado parte das características do que seria o "capitalismo moderno", voltado para a racionalidade e a impessoalidade, em que se valoriza a técnica e a indústria, e, principalmente, em que se garantem as liberdades individuais e propriedade, cabendo ao Estado a afirmação de tais garantias (FAORO, 2000b).

No capitalismo politicamente orientado haveria a proeminência do estamento, que seria formado a partir de quadros parcialmente insulados, políticos ou burocráticos, que dirigiriam as ações do Estado orientando-as para o atendimento de seus próprios interesses em detrimento do interesse público, situação que representaria o suporte social à invasão do público pelo privado (FAORO, 2000a).

[Esta] comunidade política conduz, comanda, supervisiona os negócios, como negócios privados seus, na origem, como negócios públicos depois, em linhas que se demarcam gradualmente. O súdito, a sociedade, se compreendem no âmbito de um aparelhamento a explorar, a manipular, a tosquiar nos casos extremos. Dessa realidade se projeta, em florescimento natural, a forma de poder, institucionalizada num tipo de domínio: o patrimonialismo, cuja legitimidade assenta no tradicionalismo - assim é porque sempre foi (FAORO, 2000b, p. 363).

Para a tese patrimonialista a partir das ideias de Holanda e Faoro, a corrupção no Brasil seria derivada da colonização portuguesa, cujo produto foi a persistência de um modelo institucional em que as relações sociais, políticas e econômicas ocorreriam sem que houvesse uma clara separação entre o público e o privado.

Supõe-se que a tradição política brasileira não respeita a separação entre o público e o privado, não sendo, o caso brasileiro, um exemplo de Estado moderno legitimado por normas impessoais e racionais. O patrimonialismo é a mazela da construção da República, de maneira que ele não promoveria a separação entre os meios de administração e os funcionários e governantes, fazendo com que esses tenham acesso privilegiado para a exploração de suas posições e cargos. Dado o patrimonialismo inerente à construção da cena pública brasileira, a corrupção é um tipo de prática cotidiana, chegando mesmo a ser legitimada e explícita no âmbito de uma tradição estamental e tradicional herdada do mundo ibérico (FILGUEIRAS, 2009, p. 388).

Em seu estudo sobre as principais teorias acerca das causas da corrupção, Graaf (2007) apresenta estudo comparativo entre tais teorias, considerando as seguintes dimensões de análise: elo causal, nível de análise das causas, nível de análise da corrupção, contexto e métodos de pesquisa mais comuns. A análise das teorias sobre as causas da corrupção com base na modernização, que esse autor denomina de "choque entre valores morais", resultou na Tabela 1. 
Tabela 1 - As dimensões da análise das causas da corrupção a partir da perspectiva da modernização

\begin{tabular}{l|l|l|l|l}
\hline Elo causal & $\begin{array}{l}\text { Nível de } \\
\text { análise } \\
\text { das causas } \\
\text { (variáveis } \\
\text { indepen- } \\
\text { dentes) }\end{array}$ & $\begin{array}{l}\text { Nível de } \\
\text { análise da } \\
\text { corrupção } \\
\text { (variáveis } \\
\text { dependen- } \\
\text { tes) }\end{array}$ & Contexto & $\begin{array}{l}\text { Métodos } \\
\text { de pesqui- } \\
\text { sa mais } \\
\text { comuns }\end{array}$ \\
\hline $\begin{array}{l}\text { O elo causal começa } \\
\text { com certos valores } \\
\text { da sociedade, que } \\
\text { não seriam aqueles } \\
\text { da suposta moder- } \\
\text { nidade, que influen- } \\
\text { ciam diretamente os } \\
\text { valores e as condutas } \\
\text { dos indivíduos. Esses } \\
\text { valores influenciam } \\
\text { o comportamento de } \\
\begin{array}{l}\text { autoridades e servi- } \\
\text { dores públicos, tor- } \\
\text { nando-os corruptos. }\end{array}\end{array}$ & Sociais & Sociais & $\begin{array}{l}\text { Aspectos } \\
\text { conjun- } \\
\text { turais } \\
\text { reduzidos } \\
\text { a conflitos } \\
\text { morais } \\
\text { entre os } \\
\text { valores da } \\
\text { moder- } \\
\text { nidade e }\end{array}$ & $\begin{array}{l}\text { Principal- } \\
\text { mente } \\
\text { teóricos, } \\
\text { havendo } \\
\text { poucos } \\
\text { estudos de } \\
\text { caso. }\end{array}$ \\
\hline
\end{tabular}

Fonte: Graaf (2007, p. 46).

Graaf (2007) aponta que tais teorias são predominantemente utilizadas em estudos sobre a corrupção em países subdesenvolvidos. A partir delas, tal fenômeno é entendido como resultante do antagonismo entre a moralidade pública (macro) e a moralidade privada (micro).

Micro morality has to do with connections to people in our social circles (family, friends). It is about values, norms and moral obligations in our daily personal and social lives. [...] Moral obligations in our personal lives are characterized by reciprocity: we help friends and family just as we expect them to help us. The macro morality, by contrast, emphasizes the universal. It is the product of the process [...] of universalizing morality and claims the legitimacy of its norms or institutions of the law, a universal system of formal norms (GRAAF, 2007, p. 55).

O combate à corrupção a partir dessas bases passaria pela instituição e aplicação de códigos de conduta, bem como pela promoção de treinamentos de sensibilização e formação ética, voltando-se à eliminação do clientelismo e do nepotismo na administração pública. Para a literatura baseada nessa perspectiva, a corrupção seria comumente associada ao subdesenvolvimento, o que faria com que a 
retórica sobre sua erradicação fosse relaciona à racionalização das relações Estadosociedade como meio de se buscar o desenvolvimento (GRAAF, 2007). Analisando esse posicionamento, Filgueiras (2008b) aponta que tal perspectiva estabelece a compreensão da corrupção a partir de análises dicotômicas e evolucionistas, entendendo que tal fenômeno é inerente às sociedades atrasadas. Por essas bases, então, o combate a tal fenômeno ficaria orientado para a realização de reformas voltadas à afirmação dos valores próprios da racionalidade moderna, como a adoção da burocracia profissional e da meritocracia.

No Brasil, a primeira experiência sistemática de enfrentamento da corrupção por meio da adoção da burocracia profissional se refere à reforma administrativa do Estado Novo, durante o primeiro Governo de Getúlio Vargas. Segundo Lustosa da Costa (2010, p. 97), esse processo visou à racionalização do Estado brasileiro, buscando "introduzir no aparelho administrativo do país a centralização, a impessoalidade, a hierarquia, o sistema de mérito, a separação entre o público e o privado".

\section{A nova economia institucional}

A segunda grande perspectiva baseia-se na nova economia institucional, tem o rent-seeking como conceito central para estudo da corrupção e seu marco inicial se deu com a publicação, em 1978, do livro de Susan Rose-Ackerman intitulado Corruption: a study in Political Economy. Essa perspectiva tornou-se hegemônica a partir dos anos 1990, quando instituições financeiras internacionais passaram a defender programas de reforma baseados na New Public Management (FILGUEIRAS, 2008a, 2008b; SACRAMENTO; PINHO, 2009).

Apesar de se denominar essa segunda vertente, neste trabalho, de nova economia institucional, esclarece-se que essa não tem fronteiras claras e nem uma única designação na literatura ${ }^{1}$. Como destaca Lustosa da Costa (2010, p. 139140), tal vertente é também conhecida como "neoinstitucionalismo econômico" e se relaciona a um conjunto de abordagens que "muitas vezes se justapõem, se complementam e até mesmo se confundem".

\footnotetext{
${ }^{1}$ Marques (1997, p. 95), por exemplo, indica que a corrente da literatura "neoinstitucionalista da escolha racional" que enfoca a impossibilidade de que agentes tenham conhecimento perfeito e completo das condições das transações seria intitulada de "nova economia institucional”. Autores como Douglas C. North e Oliver E. Williamson são apontados como referências tanto do novo institucionalismo econômico e da nova economia institucional (LUSTOSA DA COSTA, 2010; FIANI, 2011) quanto do institucionalismo da escolha racional (MARQUES, 1997; HALL; TAYLOR, 2003). Filgueiras (2008b, p. 357), ao tratar sobre as agendas de pesquisa sobre a corrupção, informa que aquela que seria atualmente hegemônica adotaria "as premissas da escolha racional e do novo institucionalismo". Quanto ao estudo da corrupção no campo da administração pública brasileira, Sacramento e Pinho (2009, p. 14) assentam que a abordagem mais influente seria a do "institucionalismo da escolha racional".
} 
Sobre o estudo da corrupção a partir das teorias relacionadas à nova economia institucional, Rose-Ackerman (2010) define que a essência de tal abordagem se funda na ideia de que os diferentes atores, seja no exercício de prerrogativas públicas ou na defesa de interesses privados, têm seu comportamento orientado pelo conjunto de incentivos criados pelo contexto institucional que os envolve. Para essa autora, o problema da corrupção não estaria relacionado de forma simplista a baixos níveis de democratização, mas sim à existência de situações de competição entre atores autointeressados (self-interested) que buscariam (por meios lícitos ou ilícitos) subverter decisões coletivas para a satisfação de seu próprio bem-estar, mesmo que em detrimento do interesse público, seja em ambientes autoritários ou democráticos (ROSE-ACKERMAN, 1978).

De forma geral, o estudo dos fenômenos políticos por meio das teorias relacionadas à vertente da nova economia institucional orienta-se pela concepção hobbesiana da natureza humana, tendo o racionalismo econômico e o individualismo metodológico como seus pressupostos (LUSTOSA DA COSTA, 2010). O primeiro pressuposto se relaciona ao postulado do homo æconomicos, atribuído à análise da prosperidade na teoria econômica clássica de Adam Smith, por meio do qual parte-se da premissa de que os homens racionalizam suas decisões por julgamentos amorais, orientando-se por seu interesse egoísta e comportando-se com base no utilitarismo em suas relações econômicas, sociais e políticas. O segundo parte do primeiro, sustentando-se pela ideia de que, se o indivíduo se orienta pelo seu autointeresse tanto no campo familiar quanto no profissional ou no político e se todas as decisões derivam de tal interesse, então não há decisões coletivas que derivem de um verdadeiro interesse coletivo. Portanto, as decisões coletivas devem ser compreendidas como resultantes do universo de interesses individuais dos atores que delas participem (MARQUES, 1997; LUSTOSA DA COSTA, 2010).

A partir desses pressupostos, erigem-se o conceito do rent-seeking e as teorias voltadas à compreensão da corrupção relacionadas à vertente em tela. Destacamse entre elas a teoria da escolha racional, dos incentivos, dos custos de transação, dos jogos, da escolha pública e do principal-agente.

Sobre o conceito do rent-seeking, esse tem como referências seminais os trabalhos de Gordon Tullock e Anne Krueger (FILgUeIRAS, 2008a), tendo sido cunhado com vistas à explicação do problema do consumo de recursos por conta da competição entre agentes pela obtenção ou manutenção de monopólios. Essa competição proporcionaria transferências de rendas entre diferentes grupos dentro da sociedade, rendas essas criadas artificialmente por conta da intervenção do Estado sobre os mecanismos de mercado (KRUEGER, 1974).

O rent-seeking permite a compreensão das causas da corrupção a partir da ideia de que sua prática ocorre quando os atores que exercem prerrogativas de 
Estado se locupletam por conta da existência de competição entre diferentes atores econômicos, pela obtenção ou manutenção de monopólios que Ihes propiciem transferências de renda decorrentes da intervenção governamental. Essas transferências seriam constituídas da diferença entre os preços estabelecidos a partir de monopólios estatais num arranjo institucional falho e os preços num mercado competitivo (SILVA, 2001). Por esse conceito, tais transferências seriam viabilizadas, por exemplo, a partir de lobbies e/ou do pagamento de propinas a agentes do Estado que, por suas prerrogativas, favoreceriam que agentes econômicos obtivessem delegações de monopólios estatais, permitindo o estabelecimento de preços sobredimensionados aos de um mercado perfeitamente competitivo, incluindo neles ainda os custos desses lobbies ou propinas (TULLOCK, 1967). Nesse sentido, a possibilidade do recebimento de propinas ou outras vantagens causaria também uma competição pelos cargos de Estado cujas prerrogativas viabilizassem tais transferências (KRUEGER, 1974).

Dessa forma, pelo rent-seeking, compreende-se a corrupção como um comportamento oportunista de atores amorais, que se manifesta por meio de ações, no caso, ilegais, voltadas a propiciar transferências de renda que atendam aos interesses particulares desses atores em detrimento do interesse público. Essas ações seriam resultantes de incentivos propiciados por redes de privilégios decorrentes de arranjos institucionais falhos, que permitiriam a existência de monopólios estatais, excessos de discricionariedades na condução de negócios públicos e de mecanismos inadequados ou insuficientes de accountability (KLITGAARD, 1994; SILVA, 2001).

A teoria da escolha racional aplicada à compreensão da corrupção busca interpretar como as instituições moldam o processo decisório e diminuem ou aumentam os custos relacionados, permitindo a construção de propostas de reformas institucionais que aumentem o constrangimento à busca da satisfação de interesses individuais contrários ao interesse público (MARQUES, 1997; HALL; TAYLOR, 2003). A escolha racional, tendo como objeto os processos de decisão política numa democracia e como pressupostos o racionalismo econômico e o individualismo metodológico, "é uma variante da teoria do consumidor da economia neoclássica", consistindo na aplicação de uma teoria microeconômica para a interpretação dos fenômenos políticos a partir da investigação dos interesses (LUSTOSA DA COSTA, 2010, p. 144).

A teoria dos incentivos seria um desdobramento da escolha racional, voltada à compreensão de como as decisões dos atores envolvem a consideração dos incentivos que eles possam vir a obter, a análise das recompensas possíveis (payoffs) (MARQUES, 1997). Segundo essa teoria, os pay-offs correspondem ao objeto de estudo de uma corrente específica da teoria dos incentivos aplicada à corrupção, 
a teoria da propina (bribe). Essa última entenderia que um Estado sem instituições adequadas à responsabilização de seus agentes propicia a impunidade, que, por sua vez, é vista como o grande incentivo ao comportamento corrupto (SILVA, 2001; ROSE-ACKERMAN, 2010).

A teoria dos custos de transação analisa como as instituições moldam os processos racionais de decisão, aumentando ou diminuindo as incertezas e influenciando os custos associados à diminuição dessas incertezas, tendo o fito de propor mudanças institucionais voltadas à redução desses custos (MARQUES, 1997; HALL; TAYLOR, 2003). Assim, os custos de transação podem representar, por exemplo, possíveis propinas pagas a atores públicos que atuam como "despachantes" dentro do Estado, para acelerar processos para o exercício de direitos, como licenças e alvarás. Nesse sentido, tais propinas (bribes) seriam justamente as recompensas (pay-offs) da decisão de se corromper (SILVA, 2001).

A teoria dos jogos se relaciona à escolha racional e visa analisar a tomada de decisões entre indivíduos cujas decisões afetam uns aos outros: a decisão de um afeta os resultados de outros e vice-versa. Essa teoria traz para a agenda de pesquisa da corrupção um modelo de análise de estratégias a partir dos dilemas da confiança e da previsibilidade limitada, do compartilhamento de informações entre atores em competição, do consentimento e da colaboração e do equilíbrio "ineficiente", tipicamente exemplificado pelo dilema do prisioneiro (HALL; TAYLOR, 2003; MARQUES, 1997).

A teoria da escolha pública decorre do "estudo da agregação de preferências e da decisão coletiva, o que corresponde ao ponto de vista da demanda por bens públicos" (LUSTOSA DA COSTA, 2010, p. 145). Associada à escolha racional e à teoria dos jogos, a escolha pública visa à compreensão de desenhos constitucionais e das instituições relacionadas às decisões colegiadas típicas dos processos legislativos ou eleitorais. Uma diferença entre a escolha racional e a escolha pública partiria do fato de essa segunda não se basear na ideia de que a natureza humana seja puramente utilitarista, considerando que decisões coletivas podem ser resultantes de interesses individuais tanto egoístas quanto altruísticos (ANDREWS; KouZMIN, 1998).

A teoria principal-agente tem como base o pressuposto de que a economia e a política funcionam a partir de relações contraditórias, em que tanto produtos e serviços quanto leis e políticas são resultado de interações entre atores com interesses não coincidentes. Essa teoria busca analisar como as instituições influenciam as relações entre os principais e os agentes. Os primeiros seriam os mandantes e/ou detentores de bens/direitos cujo usufruto/exercício dependeria da ação de terceiros (justamente os agentes). Os últimos seriam os mandatários eleitos e/ou designados pelos principais para empreender ações em seu nome/interesse 
e que deveriam ser remunerados para tanto (PRZEWORSKI, 2006). Instala-se, então, um desafio, o de equilibrar o poder delegado, a ação executada e a contrapartida pela execução, dado o déficit informacional do principal frente ao agente, visto que esse último deteria maiores conhecimentos sobre a execução realizada (LUSTOSA DA COSTA, 2010).

Aplicando esse dilema à compreensão da corrupção, busca-se analisar as possibilidades de agentes (políticos, burocratas e empresários) lograrem proveito de negócios públicos em detrimento dos interesses dos principais (cidadãos), em decorrência do déficit informacional (opacidade) de suas ações e da consequente deficiência dos sistemas de accountability em responsabilizá-los por eventuais falhas ou irregularidades. Pela perspectiva em tela, o ato corrupto resultaria, então, da percepção dos agentes quanto às fraquezas das instituições, visto que é com base nelas que eles calculariam se os possíveis benefícios da corrupção superariam seus eventuais custos (VIEIRA, 2006).

Nesse sentido, os níveis de corrupção seriam maiores em arranjos institucionais que estabelecessem um conjunto excessivo de monopólios e redes de privilégios e um sistema frágil de controles governamentais e sociais, de forma a delinear relações entre o Estado e a sociedade que seriam pouco orientadas pelos valores relacionados à proteção do interesse público ${ }^{2}$ e, ao mesmo tempo, à garantia da propriedade e dos contratos, gerando, por sua vez, maiores possibilidades de captura (SILVA, 2001).

As propostas de enfrentamento da corrupção baseadas nas teorias relacionadas à nova economia institucional centram-se na busca de reformas institucionais, já que as falhas dessas são as principais causas para esse fenômeno indesejado. Para Klitgaard (1994), o combate à corrupção deve contemplar ações voltadas: ao estabelecimento de procedimentos meritocráticos e impessoais para seleção de agentes (sejam servidores, formuladores de políticas ou mesmo fornecedores); à adequação das estruturas organizacionais e dos processos decisórios com vistas à segregação de funções e à mitigação das discricionariedades; à realização de ações de sensibilização sobre os malefícios da corrupção; à análise de informações sobre casos de corrupção; e à alteração da relação entre benefícios e custos da corrupção, com vistas a desmotivar o comportamento ilegal dos agentes.

2 Há estudos da corrupção a partir de tal vertente no Brasil, cujas análises articulam também pressupostos da perspectiva da modernização referentes à ideia dicotômica do desenvolvimento e sua relação com os níveis de separação entre o público e o privado. Silva (2001, p. 50), por exemplo, indica que os países da América Latina em geral, "onde grupos [...] de caçadores de renda [...] parasitários privatizam o Estado", são subdesenvolvidos institucionalmente, sendo essa uma "[...] situação na qual, numa sociedade, prevalecem as relações tradicionais de dominação, como patrimonialismo e clientelismo, em sua forma pré-moderna”. 
Silva (2001) discorre sobre a impossibilidade de se diminuir sobremaneira o monopólio e a discricionariedade próprios da atuação estatal, admitindo também a impossibilidade de se diminuir os benefícios da corrupção e de se transformar a gestão do Estado numa gestão puramente gerencial. Sendo assim, a única forma de se efetuar um combate efetivo à corrupção se daria por meio do fortalecimento das instituições de accountability, com o fito de desestimular comportamentos oportunistas. Para esse autor, a impunidade é a principal causa para a corrupção, afinal "se existe um grande incentivo à trapaça em um grupo, o resultado coletivo será um desrespeito generalizado às regras de conduta; os incentivos à propina tendem a ser elevados e a corrupção pode florescer dramaticamente" (SILVA, 2001, p. 122).

A partir do estudo de Graaf (2007) sobre as dimensões de análise das teorias da nova economia institucional sobre as causas da corrupção, que o autor denominou de teoria da escolha pública, construiu-se a Tabela 2.

Tabela 2 - As dimensões da análise das causas da corrupção a partir da perspectiva da nova economia institucional

\begin{tabular}{|c|c|c|c|c|}
\hline Elo causal & $\begin{array}{l}\text { Nível de } \\
\text { análise das } \\
\text { causas (variá- } \\
\text { veis indepen- } \\
\text { dentes) }\end{array}$ & $\begin{array}{l}\text { Nível de análi- } \\
\text { se da corrup- } \\
\text { ção (variáveis } \\
\text { dependentes) }\end{array}$ & Contexto & $\begin{array}{l}\text { Métodos } \\
\text { de pesqui- } \\
\text { sa mais } \\
\text { comuns }\end{array}$ \\
\hline $\begin{array}{l}\text { Um agente "li- } \\
\text { vre" toma uma } \\
\text { decisão racio- } \\
\text { nal (limitada) } \\
\text { que o leva a } \\
\text { um resultado } \\
\text { mais ou me- } \\
\text { nos predeter- } \\
\text { minado de se } \\
\text { corromper. }\end{array}$ & Individual & Micro e macro & $\begin{array}{l}\text { Aspectos } \\
\text { conjunturais } \\
\text { ignorados, ou } \\
\text { seja, eles não } \\
\text { podem ser } \\
\text { responsáveis } \\
\text { por desenca- } \\
\text { dear causas. } \\
\text { A corrupção } \\
\text { começa a } \\
\text { partir do } \\
\text { momento } \\
\text { em que o } \\
\text { agente toma } \\
\text { a decisão. }\end{array}$ & $\begin{array}{l}\text { Comumente } \\
\text { teóricos }\end{array}$ \\
\hline
\end{tabular}

Fonte: Graaf (2007, p. 45).

A vantagem dessa perspectiva, segundo Graaf (2007), refere-se à sua capacidade de se concentrar na situação específica, verificar as causas diretas e indicar as intervenções pontuais. Por outro lado, essa perspectiva desconsidera fatores organizacionais e sociais e ignora as diferenças de comportamentos entre indivíduos 
expostos a um mesmo contexto institucional (por que há funcionários que, numa mesma posição de uma dada organização, se corrompem enquanto outros não?). Anechiarico e Jacobs (1996) sustentam que os programas de combate à corrupção com base nessa perspectiva focam-se no acirramento de atividades de vigilância e punição sobre agentes, como meio de se promover o aumento dos custos das atividades de corrupção para desestimular condutas ímprobas.

Observando as análises de Lustosa da Costa (2010) e Paula (2005), verificase que as bases teóricas e conceituais relacionadas ao ideário da New Public Management, que orientou a reforma do aparelho de Estado brasileiro, iniciada em 1995, identificam-se com as teorias ligadas à nova economia institucional aplicadas para análise da corrupção.

Buscando-se as palavras do principal idealizador dessa reforma acerca das justificativas para sua formulação e implementação no que tange ao combate à corrupção, vê-se que, para Bresser-Pereira (2006, p. 26), a "administração pública burocrática" só foi adequada no enfrentamento desse fenômeno enquanto as práticas a ele relacionadas eram sustentadas pela permanência do patrimonialismo; enquanto havia certa "incapacidade ou relutância de o príncipe distinguir entre o patrimônio público e seus bens privados".

Dessa forma, a administração pública gerencial, paradigma buscado pela reforma iniciada nos anos 1990, seria necessária sob o argumento da suposta ocorrência de uma mudança da predominância da modalidade de "privatização" do público no Brasil, que teria passado a se manifestar por práticas de rent-seeking. Nesse sentido, a necessidade de se superar o paradigma da administração pública burocrática se sustentaria sobre o argumento de que essa já estaria inadequada para a proteção da res publica.

O rent-seeking é quase sempre um modo mais sutil e mais sofisticado de privatizar o Estado e exige que se usem novas contraestratégias. A administração gerencial; a descentralização; a delegação de autoridade e de responsabilidade ao gestor público; o rígido controle sobre o desempenho, aferido mediante indicadores acordados e definidos por contrato, além de serem modos muito mais eficientes de gerir o Estado, são recursos muito mais efetivos na luta contra as novas modalidades de privatização do Estado (BRESSER-PEREIRA, 2006, p. 29).

\section{Os limites das perspectivas analisadas}

Observando os resultados de duas pesquisas realizadas em 2008 e 2009, Bignotto (2011) verifica que a opinião pública indica que a corrupção é uma das grandes mazelas da sociedade brasileira. Considerando a relevância do tema, o autor alerta sobre a necessidade de que sejam realizados estudos sistemáticos sobre a corrupção 
no Brasil, com vistas à melhor compreensão de sua extensão e profundidade, visto que as perspectivas que aplicam os conceitos do patrimonialismo e do rent-seeking, apesar de apresentarem determinados "ganhos de inteligibilidade do processo de corrupção [...], terminam por esconder a concepção política implícita em cada uma das abordagens, [conduzindo o estudo desse fenômeno] por meio de uma noção de falta" (BIgNOTTO, 2011, p. 15).

Especificamente sobre as possíveis limitações da compreensão da corrupção no Brasil a partir da perspectiva da modernização, Souza (2008) defende que o estudo de tal fenômeno pelo patrimonialismo gera uma visão simplificada e distorcida sobre a realidade social brasileira, que demoniza o Estado e idealiza aquele que seria seu suposto contraponto, o mercado. Tal simplificação encobre as questões sociais e políticas que envolvem as disputas entre classes e grupos por recursos nas arenas da sociedade, fazendo com que se deixe "de ter 'interesses e ideias em conflito' e [se passe] a ter um mundo político dividido entre 'honestos' e 'corruptos'" (SouzA, 2008, p. 87).

A principal consequência da centralidade do conceito de patrimonialismo entre nóse, portanto, também do tema da corrupção como característica atávica da sociedade brasileira é, certamente, o extraordinário empobrecimento do debate acadêmico e político brasileiro atual (SOUZA, 2008, p. 82).

Avritzer e Filgueiras (2011, p. 8) apontam que o uso do patrimonialismo para explicar a corrupção no Brasil acaba por estreitar o entendimento desse fenômeno, naturalizando-o e atribuindo-o ao Estado e à cultura política, o que proporciona "um engessamento crítico das instituições políticas". Essa abordagem sobre a corrupção decorre de uma suposta perspectiva moralista que produz

um tipo de histeria ética calcada em um clamor por maior moralização da política e da sociedade no Brasil. Se a corrupção for algo natural ao caráter do brasileiro, esse clamor moral promove um estado de paralisia, uma vez que a consequência desse tipo de leitura é não refletir a respeito da mudança (AVRITZER; FILgUeIRAS, 2011, p. 8)

Essa perspectiva moralista acarreta uma visão sobre a política no Brasil tomada pelo viés de indiferença por parte dos cidadãos, promovendo um sentido de neutralidade da sociedade perante o exercício do poder político, já tido como permeado pelo imoral (FILGUEIRAS, 2009).

Sobre os possíveis limites das teorias relacionadas à nova economia institucional, Marques (1997) e Andrews e Kouzmin (1998) indicam a existência de dúvidas sobre sua aplicabilidade, destacando não só as limitações de sua capacidade descritiva, mas também do caráter normativo dela decorrente. Primeiramente, o pressuposto do autointeresse utilitarista ignora as dimensões altruístas, lúdicas e simbólicas do 
homem e de seus efeitos no mundo real, mesmo que no econômico. Já o pressuposto do racionalismo ignora questões sobre as estruturas e os processos de pensamento, a orientação ideológica e a insuficiência de informações. A orientação microeconômica e a teoria dos jogos desnaturalizam o agir político e desconsideram aspectos amplos das decisões coletivas e da própria complexidade do processo de construção de decisões no nível individual psicoemocional e cognitivo (LUSTOSA DA COSTA, 2010).

Especificamente sobre os possíveis limites da compreensão da corrupção a partir das teorias relacionadas a tal vertente, Graaf (2007) sustenta que as teorias de tal perspectiva ignoram algumas questões contextuais sociais, políticas ou econômicas que podem constituir o conjunto de causas relevantes da corrupção. Os programas anticorrupção orientados por essa perspectiva comumente são receituários baseados em políticas padronizadas de "tolerância zero", sem maiores estudos críticos, centrando-se no aumento dos custos da corrupção por meio do incremento de atividades de vigilância e punição (ANECHIARICO; JACOBS, 1996; GRAAF, 2007). Esses programas são comumente sustentados pela retórica de terem sido elaborados a partir de casos de sucesso que os legitimam como "testados na prática" e acabam sendo aplicados indistintamente entre os diferentes países, independentemente de suas particularidades (POLZER, 2001; BIGNOTTO, 2011).

Anechiarico e Jacobs (1996) alertam que esses receituários orientam o pensamento sobre o combate à corrupção a uma ideia de que esse fenômeno simplesmente diminui à proporção em que o controle aumenta, sem considerar outras variáveis e sem buscar levantar os possíveis efeitos marginais de sua implementação. Aumentados os controles sobre um processo ou órgão, esse tenderá a diminuir sua eficácia, considerando a mobilização de pessoas, o tempo e os recursos que sempre são necessários para, por exemplo, a realização de prestações de contas ou para o atendimento de auditores.

Sobre os limites comuns a essas duas perspectivas, Filgueiras (2008b) assenta que o debate sobre a corrupção, quando orientado tendo o Estado como problema e o mercado como horizonte fundamental, é levado a uma discussão que naturaliza esse fenômeno, pondo-o como corriqueiro, como uma situação comum às sociedades pouco institucionalizadas.

Acreditamos que a concepção econômica da política democrática cria uma miopia teórica a respeito da corrupção. É fundamental compreender que a linguagem da economia colonizou o discurso político, fazendo com que a teoria e a prática da política sejam exclusivamente as articulações dos interesses em uma lógica de competição e cooperação de atores racionalmente orientados pelos fins. O resultado é a naturalização do conceito de corrupção pela lógica dos interesses e de seus equivalentes funcionais delimitados pelo Direito [...] (FILGUEIRAS, 2008b, p. 359). 
Assim, o primeiro ponto em comum dessas perspectivas é que, seja no trato cordial da coisa pública, seja com base na ideia do autointeresse utilitarista, elas partem da premissa de que o fenômeno da corrupção seria principalmente o resultado dos incentivos decorrentes de arranjos institucionais que não conseguiriam moldar a conduta dos agentes do Estado pelos valores da impessoalidade e da integridade. Dessa forma, baseiam-se numa "antropologia dos interesses" que analisa a corrupção a partir da racionalidade inerente ao econômico e atribui sobremaneira seu combate ao campo do Direito (FILGUEIRAS, 2008a, 2008b). A visão sobre a corrupção e seu espaço no Brasil a partir dessas perspectivas dá a ideia de que seu combate deva ser retirado da ordem do político para a ordem jurídica, mais especificamente para a dimensão penal, com vistas a transferir à lei a responsabilidade pelo controle das autoridades e dos servidores (AVRITZER; FILGUEIRAS, 2011).

Filgueiras (2009) alerta que o pressuposto de que o combate à corrupção passa simplesmente pela criminalização de suas práticas em contraposição simultânea às situações cotidianas de necessidade impostas aos cidadãos brasileiros (carga tributária alta, insegurança econômica, aumento da criminalidade, deterioração dos serviços públicos de saúde etc.) gera uma antinomia entre as normas morais e as práticas sociais e, consequentemente, certa tolerância da sociedade frente a esse fenômeno indesejado.

Um segundo ponto em comum decorre do fato de que seus pressupostos guiam o estudo da corrupção pela ideia de que tal fenômeno seria inerente à política. Pressupondo que o processo de definição da agenda pública se dá a partir de bases não racionais, o debate sobre a corrupção redunda na desconfiança quanto à atuação dos agentes do campo político e da burocracia e na defesa pela diminuição de monopólios estatais (FILGUEIRAS, 2008a). Dessa forma, tais perspectivas fundam-se na ideia a priori de que haveria uma diminuição das práticas corruptas pela supressão do excesso de autoridade do Estado sobre a economia e a liberação das forças de mercado. Entretanto, há na literatura diversos estudos que indicam que as reformas para o mercado não conseguiram diminuir os níveis de corrupção nos países em desenvolvimento em que foram implementadas (GRAAF, 2007; REHEN, 2009).

Um terceiro ponto é que tais perspectivas partem de um referencial de ideal do capitalismo moderno, tratando a corrupção como o reflexo de um gap frente à modernidade capitalista (FILGUEIRAS, 2008b). A questão é que o caráter normativo de tais teorias leva ao apontamento que põe o capitalismo avançado como o objetivo de desenvolvimento de qualquer sociedade, sendo que: mesmo os países tidos como economias capitalistas avançadas apresentam limites e contradições; é inerente a quaisquer sociedades o fato de apresentarem particularidades políticas, 
culturais, sociais e econômicas; e tais particularidades não são necessariamente boas ou ruins em si (SOUZA, 2008; BIGNOTTO, 2011).

Dessa maneira, pode-se restringir a tentativa de se compreender a corrupção no Brasil ao mero estudo comparativo entre sociedades, em que se busca basicamente - levantamento das características daquelas consideradas menos corruptas, transformando-as em "modelos a serem seguidos" (SOUZA, 2008; BIGNOTTO, 2011). Nesse sentido, a adoção acrítica de tais vertentes pode simplificar a discussão sobre a gênese e o local da corrupção, atribuindo-a simplesmente ao Estado, provocando um esquecimento das questões políticas e sociais anteriores à existência de monopólios e à efetividade dos sistemas formais de accountability.

O que não podemos aceitar é reduzir nossos estudos apenas ao Estado, como se a sociedade e os interesses privados, expressos pelo mercado, fossem, em si próprios, legítimos e infensos à corrupção. Ora, no caso brasileiro, é justamente essa permeabilidade entre as duas esferas e a ausência de controle sobre os canais de realização dos interesses privados, o que corrói o tecido político (BIGNOTTo, 2011, p. 33)

Graaf (2007) destaca o fato de que tais perspectivas, por desconsiderarem parte dos fatores políticos, econômicos e culturais que seriam fundamentais para a compreensão da corrupção em diferentes países, regiões, localidades ou mesmo organizações, engendrariam modelos de análise redutores. Esses modelos não articulariam todas as diferentes variáveis de nível social (macro), organizacional (meso) e individual (micro), relacionadas ao conjunto de causas relevantes para a ocorrência de tal fenômeno. Esse autor apresenta algumas noções no que tange à consideração de tais níveis para análise das causas da corrupção, a partir das seguintes ideias que atribui a L. W. J. C. Huberts:

When discussing fraud and corruption in the police force, he states that three levels of factors are at play. At the micro level are those that deal with individuals and their work. At the meso level are characteristics of the organization, which are distributed among leadership, organization structure, personal policy and organization culture. Third, there is a whole range of factors on the macro level, including changes in criminality, rules and laws, and so on (GRAAF, 2007, p. 67).

Tomando-se esses apontamentos, a lógica das Tabelas 1 e 2 e a análise das características e das críticas das perspectivas em tela, construiu-se a Tabela 3. Produto do apanhado das causas, das situações de ocorrência e das medidas de combate construídas a partir das perspectivas analisadas, tal tabela indica, não exaustivamente, as questões que não seriam alcançadas para a compreensão mais ampla do fenômeno da corrupção, segundo a literatura crítica pesquisada. 
Tabela 3 - Características e limites da aplicação das perspectivas analisadas para análise da corrupção

\begin{tabular}{|c|c|c|c|c|}
\hline Perspectiva & Causas & $\begin{array}{l}\text { Situação de } \\
\text { ocorrência }\end{array}$ & $\begin{array}{l}\text { Medidas de } \\
\text { combate }\end{array}$ & $\begin{array}{l}\text { Questões não } \\
\text { alcançadas } \\
\text { na análise da } \\
\text { corrupção }\end{array}$ \\
\hline Modernização & $\begin{array}{l}\text { Arranjo } \\
\text { institucional } \\
\text { incompati- } \\
\text { vel com a } \\
\text { moderni- } \\
\text { dade (nível } \\
\text { macro). }\end{array}$ & $\begin{array}{l}\text { No exercício } \\
\text { de prerrogati- } \\
\text { vas de Estado } \\
\text { ou na gestão } \\
\text { de bens ou } \\
\text { serviços pú- } \\
\text { blicos quando } \\
\text { não há clara } \\
\text { separação en- } \\
\text { tre o público e } \\
\text { o privado. }\end{array}$ & $\begin{array}{l}\text { Reformas } \\
\text { voltadas à } \\
\text { afirmação } \\
\text { da impesso- } \\
\text { alidade e à } \\
\text { sensibiliza- } \\
\text { ção acerca } \\
\text { dos valores } \\
\text { públicos. }\end{array}$ & \multirow{2}{*}{$\begin{array}{l}\text { Singularidades } \\
\text { culturais nacio- } \\
\text { nais, regio- } \\
\text { nais, locais e } \\
\text { organizacionais } \\
\text { (níveis macro e } \\
\text { meso). } \\
\text { Questões de } \\
\text { relações inter- } \\
\text { nacionais, go- } \\
\text { vernabilidade } \\
\text { e governança } \\
\text { entre e nas es- } \\
\text { feras, poderes, } \\
\text { órgãos, entida- } \\
\text { des e unidades } \\
\text { (níveis macro e } \\
\text { meso). } \\
\text { Condições e } \\
\text { fatores indivi- } \\
\text { duais (níveis } \\
\text { micro). }\end{array}$} \\
\hline $\begin{array}{l}\text { Nova } \\
\text { economia } \\
\text { institucional }\end{array}$ & $\begin{array}{l}\text { Arranjo } \\
\text { institucional } \\
\text { inadequa- } \\
\text { do, com } \\
\text { excesso de } \\
\text { monopólios } \\
\text { e discricio- } \\
\text { nariedade e } \\
\text { accountabi- } \\
\text { lity defi- } \\
\text { ciente (nível } \\
\text { macro). }\end{array}$ & $\begin{array}{l}\text { Quando há } \\
\text { excesso de } \\
\text { interferência } \\
\text { do Estado } \\
\text { e do exercí- } \\
\text { cio de suas } \\
\text { prerrogativas, } \\
\text { e controles } \\
\text { insuficientes } \\
\text { sobre a atua- } \\
\text { ção dos atores } \\
\text { que condu- } \\
\text { zem negócios } \\
\text { públicos } \\
\text { (níveis macro } \\
\text { e micro). }\end{array}$ & $\begin{array}{l}\text { Reformas } \\
\text { voltadas à } \\
\text { diminuição } \\
\text { de mono- } \\
\text { pólios e } \\
\text { discriciona- } \\
\text { riedades e } \\
\text { ao acirra- } \\
\text { mento das } \\
\text { atividades } \\
\text { de vigilância } \\
\text { e punição. }\end{array}$ & \\
\hline
\end{tabular}

Fonte: Elaboração própria.

Sobre a primeira questão apresentada na última coluna da Tabela 3, assentase que aspectos culturais nacionais, regionais, locais ou mesmo organizacionais, que poderiam indicar a existência de possíveis conflitos de valores ou deficiências institucionais, não se relacionam simplesmente à dicotomia desenvolvimento/ subdesenvolvimento ou institucionalizado/não institucionalizado, mas, sim, às moralidades construídas a partir do político e do simbólico, inscritos na história e nas relações sociais (BıGNOTTO, 2011). Não observar tais aspectos significaria analisar casos de corrupção desconsiderando, por exemplo, as diferenças culturais entre órgãos de funções e climas organizacionais diversos, como a Polícia Federal, 
o Departamento Nacional de Infraestrutura (DNIT) e a Agência Nacional do Cinema (Ancine).

Sobre a segunda questão, alguns aspectos ligados à governabilidade e que podem ser cruciais para a compreensão das condições de ocorrência da corrupção também não seriam alcançados por essas vertentes. A análise, por exemplo, das causas relativas à existência do uso clientelista de transferências governamentais voluntárias (BROLLO; NANNICCI, 2012) ficaria prejudicada pela abordagem da modernização, tendo em vista que esse tipo de relação entre governos nacionais e subnacionais não é uma exclusividade dos países "atrasados". Pelas teorias relacionadas à nova economia institucional, a análise de tal fenômeno tenderia a se ater à busca por falhas nos sistemas de accountability, deixando de lado questões sobre as bases do federalismo nos diferentes países ou o funcionamento de suas estruturas político-partidárias. Refletindo-se sobre os aspectos relacionados à governança e que ficariam prejudicados, pode-se apontar que os modelos de análise engendrados pelas duas vertentes analisadas desconsiderariam as particularidades marcantes na gestão e na estrutura de organizações com missões, processos, recursos e usuários diferentes, como, por exemplo, entre unidades de saúde e empresas estatais relacionadas à área de petróleo e gás natural.

Sobre a terceira questão, quanto às condições e fatores individuais, esses se referem à consideração das características contingenciais ou permanentes dos agentes envolvidos em casos de corrupção, que, mesmo individuais, podem ser indicativos de questões sociais maiores.

Considerando, então, que os modelos de análise das perspectivas analisadas não articulam alguns fatores que podem ser elementos relevantes do conjunto de causas para a ocorrência e permanência de práticas de corrupção, entende-se que possíveis estratégias de combate à corrupção fundadas a partir de tais modelos podem mostrar-se também limitadas. Essa situação indicaria que as políticas anticorrupção baseadas nas vertentes em tela poderiam ter sua efetividade comprometida, mesmo porque o combate a tal fenômeno no Brasil envolve

“questões 'caras' à democracia e à cidadania, como a representatividade e a participação da sociedade na formação da agenda política, a regulação dos mercados e agentes econômicos, o desequilíbrio regional, as desigualdades econômicas e sociais e a própria relação Estado-sociedade" (OLIVEIRA JÚNIOR; Mendes, 2014, p. 6).

Destaca-se uma última questão sobre essas duas vertentes, mais especificamente sobre os estudos realizados a partir de suas bases. Em sua pesquisa bibliográfica acerca das principais teorias sobre as causas da corrupção abordadas pela literatura especializada, Graaf (2007) destacou que os ensaios teóricos sobre tal fenômeno 
seriam muito mais numerosos do que as pesquisas empíricas. Por esse motivo, alerta sobre a necessidade de que sejam realizados mais estudos aplicados sobre casos concretos, questão que dependeria da sensibilização e da ação de scholars e de practitioners ligados ao controle da corrupção.

\section{Alternativas às perspectivas analisadas}

O apontamento de uma alternativa às perspectivas analisadas passa pelo desafio de se encontrar uma abordagem abrangente, que considere os diversos fatores que podem estar associados ao conjunto de causas relevantes da corrupção nas diferentes sociedades (países, regiões, localidades ou mesmo organizações) e que permita que se engendre um modelo de análise capaz de articular as variáveis de diferentes níveis relacionadas a esses fatores. Na busca por uma perspectiva que permita tal compreensão e leve em consideração as possíveis singularidades políticas, sociais, econômicas e culturais que possam ser relevantes para as práticas de corrupção, encontrou-se a possibilidade de aplicação da teoria da ação social de Bourdieu.

The research on corruption using Bourdieu's theory of action should focus on the categories of perception, appreciation and the lived experience [...] of corrupt officials. This can be called a disposition analysis, in which the habitus of the corrupt official is analyzed (GRAAF, 2007, p. 72-73).

Nesse sentido, casos concretos de corrupção podem ser analisados a partir do conceito de habitus e outros a ele relacionados, como estrutura, campo, prática e disposição, cuja aplicação permitiria a síntese de um modelo de compreensão da corrupção, considerando as variáveis de todos os níveis. Observados os sentidos atribuídos à ideia do habitus por Bourdieu (1987, 1996, 2013), vê-se que tal conceito aplicado à compreensão das práticas de corrupção pode propiciar explicações sobre as razões para as distinções dos casos concretos entre diferentes áreas de governo, a existência de órgãos e carreiras mais suscetíveis a ela, a estrutura e a lógica dos possíveis esquemas de corrupção e a recorrência e a permanência desse fenômeno a despeito de ser ele proibido pelos ordenamentos jurídicos das democracias contemporâneas.

Produto da história, o habitus produz práticas, individuais e coletivas, portanto, da história, conforme aos esquemas engendrados pela história; ele garante a presença ativa das experiências passadas que, depositadas em cada organismo sob a forma de esquemas de percepção, pensamento e ação, tendem, de forma mais segura que todas as regras formais e que todas as normas explícitas, a garantir a conformidade das práticas e sua constância ao longo do tempo (BOURDIEU, 2013, p. 90). 
Conforme se apresenta na Tabela 4, a aplicação da teoria da ação social para a compreensão do fenômeno da corrupção pode fornecer um modelo da ação social que incorpora os fatores relacionados às causas desse fenômeno nos níveis micro, meso e macro, permitindo uma análise articulada das disposições objetivas que compõem as causas da corrupção.

Tabela 4 - As dimensões da análise das causas da corrupção a partir da perspectiva da teoria da ação social de Bourdieu

\begin{tabular}{l|l|l|l|l}
\hline Elo causal & $\begin{array}{l}\text { Nível de } \\
\text { análise } \\
\text { das causas } \\
\text { (variáveis } \\
\text { indepen- } \\
\text { dentes) }\end{array}$ & $\begin{array}{l}\text { Nível de } \\
\text { análise da } \\
\text { corrupção } \\
\text { (variável } \\
\text { dependente) }\end{array}$ & Contexto & $\begin{array}{l}\text { Métodos } \\
\text { de pesqui- } \\
\text { sa mais } \\
\text { comuns }\end{array}$ \\
\hline $\begin{array}{l}\text { Uma pessoa inseri- } \\
\text { da em um determi- } \\
\text { nado habitus, tendo } \\
\text { certas disposições e } \\
\text { predisposições. }\end{array}$ & $\begin{array}{l}\text { Todos os } \\
\text { níveis }\end{array}$ & Individual & $\begin{array}{l}\text { Contexto, } \\
\text { conjuntura } \\
\text { e contingên- } \\
\text { cias do caso } \\
\text { concreto. }\end{array}$ & $\begin{array}{l}\text { Estudo de } \\
\text { caso }\end{array}$ \\
\hline
\end{tabular}

Fonte: Graaf $(2007$, p. 70).

Graaf (2007) afirma que, com as categorias de Bourdieu, pode-se vincular o global com o local, tendo o habitus como o elo de mediação entre estrutura social (macro e meso) e ação individual (micro).

Dessa forma, por essa vertente, a prática da corrupção ocorre quando se combina um conjunto necessário de fatores macro, meso e micro, o sistema de disposições (que seria o próprio habitus). Essas disposições não excluem o comportamento e os valores sociais e culturais dos indivíduos, visto que há fatores sociais que funcionam por meio deles (GRAAF, 2007). Esse modelo de compreensão é próprio da perspectiva epistemológica do estruturalismo construtivista, orientando-se pela ideia de que

[...] existem, no próprio mundo social e não apenas nos sistemas simbólicos - linguagem, mito, etc. -, estruturas objetivas, independentes da consciência e da vontade dos agentes, as quais são capazes de orientar ou coagir suas práticas e representações [...], sendo que há, de um lado, uma gênese social dos esquemas de percepção, pensamento e ação que são constitutivos do que chamo de habitus e, de outro lado, as estruturas sociais, em particular o que chamo de campos e grupos [...] (BourdieU, 1987, p. 149).

Como aborda Thiry-Cherques (2006), o quadro referencial formado pelo habitus leva a investigações eminentemente empíricas. Segundo esse autor, as pesquisas 
orientadas pelo estruturalismo construtivista bourdiano devem buscar construir um modelo de compreensão que represente a estrutura (não necessariamente explícita) e o habitus que regem o campo investigado. Essa construção passa por "um percurso epistemológico que vai do 'racional ao real' e não do 'real ao geral'" (THIRY-CHERQUES, 2006, p. 42). Tal modelo partiria da construção prévia do esquema de relações e da análise das relações objetivas, para, então, realizar a análise do sistema de disposições (o habitus) e a construção de uma matriz relacional não necessariamente visível (a estrutura).

Bourdieu e Wacquant (2005) informam sobre quais seriam os objetivos e os passos para a realização de uma análise de fenômenos por meio da teoria da ação social bourdiana, assentando que

Un análisis, en términos de campo, implica tres momentos necesarios e internamente conectados (Bourdieu 197ld). Primero, se debe analizar la posición del campo frente al campo del poder. [...] Segundo, es necesario trazar un mapa de la estructura objetiva de las relaciones entre las posiciones ocupadas por los agentes o instituciones que compiten por la forma legítima de autoridad específica del campo. Y, tercero, hay que analizar los habitus de los agentes, los diferentes sistemas de disposiciones que han adquirido al internalizar un determinado tipo de condición social y económica, condición que encuentra en su trayectoria dentro del campo oportunidades más o menos favorables de actualización (BOURDIEU; WACQUANT, 2005, p. 159-160).

Dessa maneira, essa perspectiva parece alcançar as questões tidas como fundamentais para a compreensão da corrupção no Brasil, relativas às singularidades culturais, políticas, sociais e econômicas, conseguindo engendrar um modelo de compreensão que articula os fatores relacionados às causas de tal fenômeno em diferentes níveis.

A questão que se destaca sobre sua aplicação no que tange à pesquisa bibliográfica realizada é que, no conjunto de estudos que serviram de fonte, não foram encontradas quaisquer referências sobre experiências de aplicação dessa teoria para análise de casos práticos de corrupção. Assim, não há informações, a priori, sobre a verificação empírica de sua validade, aplicabilidade e abrangência.

Atenta-se, ainda, que a perspectiva proposta se restringe a estudos de caso. Nesse sentido, sua abordagem em tese não gera, por si, informações que possam orientar políticas de anticorrupção. Entende-se que somente após sua aplicação em numerosos e diferentes casos concretos de corrupção poderá se delinear, a partir dos modelos de análise nela baseados, estratégias para se buscar aumentar a efetividade do combate à corrupção no Brasil. 


\section{Conclusões}

Este trabalho traça um panorama das principais perspectivas teóricas que orientam a análise do fenômeno da corrupção no campo da administração pública brasileira, investiga seus limites e busca alternativas que os transponham. A primeira perspectiva, que foi predominante até os anos 1990, baseia-se na noção de modernização e centra-se no conceito do patrimonialismo. A segunda, hoje hegemônica, relaciona-se à nova economia institucional e tem o rent-seeking como o principal conceito para o estudo da corrupção.

Realizada por meio de pesquisa bibliográfica, a análise da primeira perspectiva orientou-se primariamente pelos clássicos daquela vertente na literatura brasileira. Sobre a segunda, sua análise partiu dos estudos dos autores mais referenciados no campo da administração pública brasileira. Utilizaram-se também os estudos de outros autores que debatem as características e os limites de tais perspectivas para a compreensão da corrupção.

A literatura crítica sobre o tema aponta a existência de determinados limites nas perspectivas em comento. Por desconsiderarem parte dos fatores políticos, econômicos e culturais que seriam fundamentais para a compreensão da corrupção nas diferentes sociedades ou mesmo organizações, seus modelos de análise não articulariam todas as variáveis de nível macro, meso e micro que constituiriam o conjunto de causas relevantes de tal fenômeno.

Por conta desses limites, a compreensão da corrupção por meio das perspectivas analisadas passa ao largo de questões fundamentais acerca da ocorrência e da permanência de práticas relacionadas a esse fenômeno no Brasil. Consequentemente, possíveis políticas de anticorrupção a partir delas fundadas podem ter sua efetividade comprometida.

Indicada como possível alternativa, a teoria da ação social de Bourdieu parece transpor tais limites. A questão sobre essa alternativa é que não foram encontradas referências de aplicações anteriores para análise de casos concretos. Além disso, por restringir-se a estudos de caso, somente após sua aplicação em certo número de casos concretos seria possível delinear estratégias de combate com base em seus resultados. 


\section{Bibliografia}

ANDREWS, C. W.; KouzMin, A. O discurso da nova administração pública. Lua NovaRevista de Cultura e Política, n. 45, p. 97-127, 1998.

ANECHIARICO, F.; JACOBS, J. B. The pursuit of absolute integrity: how corruption controls make government ineffective. Chicago: The University of Chicago Press, 1996.

AVRItZer, L.; FilgueIRAS, F. Corrupção e controles democráticos no Brasil. Brasília: Cepal - Escritório no Brasil/Ipea, 2011.

BIgnotto, N. Corrupção e opinião pública. In: AVRITZER, L.; FILGUEIRAS, F. Corrupção e sistema político no Brasil. Rio de Janeiro: Civilização Brasileira, 2011. p. 15-43.

BourdieU, P. Coisas ditas. São Paulo: Brasiliense, 1987.

BouRdieU, P. Razões práticas. Campinas: Papirus, 1996.

Bourdieu, P. O senso prático. Petrópolis: Vozes, 2013.

BOURDIEU, P.; WACQUANT, L. El propósito de la sociología reflexiva. In: BouRdiEU, P. Una invitación a la sociología reflexiva. Buenos Aires: Siglo XXI Editores, 2005. p. 101-300.

BRESSER-PEREIRA, L. C. Gestão do setor público: estratégia e estrutura para um novo Estado. In: BRESSER-PEREIRA, L. C.; SPINK, P. K. Reforma do Estado e administração pública gerencial. Rio de Janeiro: Editora FGV, 2006. p. 21-38.

BRolLO, F.; NANNICCI, T. Tying your enemy's hands in close races: the politics of federal transfers in Brazil. American Political Science Review, v. 106, n. 4, p. 742761, 2012.

CARvalho, J. M. Passado, presente e futuro da corrupção brasileira. In: AVRITZER, L. et al. Corrupção: ensaios e críticas. Belo Horizonte: Editora UFMG, 2008. p. 237-242. FAORO, R. Os donos do poder: formação do patronato político brasileiro. 10a . ed. São Paulo: Globo/Publifolha, v. I, 2000a.

FAORO, R. Os donos do poder: formação do patronato político brasileiro. 10a . ed. São Paulo: Globo/Publifolha, v. II, 2000b.

FIANI, R. Cooperação e conflito: instituições e desenvolvimento econômico. Rio de Janeiro: Elsevier, 2011.

FILGUEIRAS, F. Corrupção, democracia e legitimidade. Belo Horizonte: Editora UFMG, 2008a.

FILGUeIRAS, F. Marcos teóricos da corrupção. In: AVRITZER, L. et al. Corrupção: ensaios e crítica. Belo Horizonte: Editora UFMG, 2008b. p. 353-361.

FILGUeIRAS, F. A tolerância à corrupção no Brasil: uma antinomia entre normas morais e prática social. Revista Opinião Pública, Campinas, 15, n. 2, p. 386-421, 2009.

GRAAF, G. Causes of corruption: towards a contextual theory of corruption. Public Administration Quarterly, v. 31, n. 1, p. 39-86, 2007.

GRAAF, G.; MARAVIĆ, P.; WAGENAAR, P. Introduction: causes of corruption - the right question or the right perspective? In: GRAAF, G.; MARAVIĆ, P.; WAGENAAR, P. The good 
cause: theoretical perspectives on corruption. Farmington Hills: Barbara Budrich Publishers, 2010. p. 13-20.

HALL, P. A.; TAYLOR, R. C. As três versões do neo-institucionalismo. Lua Nova-Revista de Cultura e Política, São Paulo, n. 58, p. 193-223, 2003.

HolandA, S. B. Raízes do Brasil. São Paulo: Companhia das Letras, 1995.

KLITGAARD, R. A corrupção sob controle. Rio de Janeiro: Jorge Zahar, 1994.

KRUEGER, A. The political economy of the rent-seeking society. The American Review, v. 64, n. 3, p. 291-303, 1974.

LUSTOSA DA COSTA, F. Reforma do Estado e contexto brasileiro: crítica do paradigma gerencialista. Rio de Janeiro: Editora FGV, 2010.

MARques, E. C. Notas críticas à literatura sobre Estado, políticas estatais e atores políticos. Revista Brasileira de Informação Bibliográfica em Ciências Sociais, Rio de Janeiro, n. 43, p. 67-102, 1997.

OliVeIRA JúnIOR, T. M.; Mendes, A. P. Corrupção e combate à corrupção no Brasil: abordagens e limitações. Encontro da Anpad, 38., 2014, Rio de Janeiro. Anais... Rio de Janeiro: Associação Nacional de Pós-Graduação e Pesquisa em Administração, 2014.

PAULA, A. P. Por uma nova gestão pública: limites e potencialidades da experiência contemporânea. Rio de Janeiro: Editora FGV, 2005.

POLZER, T. Corruption: deconstruction the World Bank discourse. London School of Economics and Political Science Website, 2001. Disponivel em: <http://www. grammatikhilfe.com/internationalDevelopment/pdf/WP/WP18.pdf>. Acesso em: 6 ago. 2014.

PRZEWORSKI, A. Sobre o desenho do Estado: uma perspectiva agent $X$ principal. In: BRESSER-PEREIRA, L. C.; SPINK, P. K. Reforma do Estado e administração pública gerencial. Rio de Janeiro: Edito FGV, 2006. p. 39-73.

REHEN, A. The crisis of the Democratic State. In: BLAKE, C. H.; MoRRIS, S. D. Corruption \& Democracy in Latin America. Pittsburgh: University of Pittsburgh Press, 2009.

Rose-ACKerman, S. Corruption: a study in Political Economy. Nova lorque: Academic Press, 1978.

ROSE-ACKERMAN, S. The institutional economics of corruption. In: GrAAF , G.; MARAVIC, P.; WAGENAAR, P. The good cause: theoretical perspectives on corruption. Barbara Falls, MI, EUA: Barbara Budrich Publishers, 2010. p. 47-63.

Sacramento, A. R. S.; Pinho, J. A. G. A produção acadêmica brasileira sobre corrupção em administração pública: um estudo no período compreendido entre 1997 e 2008. In: EnAnpad, 33., 2009, São Paulo. Anais... São Paulo: Anpad, 2009.

Sılva, M. F. G. D. A economia política da corrupção no Brasil. São Paulo: Editora Senac, 2001.

SouzA, J. Weber. In: AVRItzer, L. et al. Corrupção: ensaios e críticas. Belo Horizonte: Editora UFMG, 2008. p. 81-90.

ThIRY-Cherques, H. R. Pierre Bourdieu: a teoria na prática. Revista da Administração Pública, Rio de Janeiro, v. 40, n. 1, p. 27-55, 2006. 
TULLOCK, G. The welfare costs do tariffs, monopolies, and theft. Western Economic Journal, v. 5, n. 3, p. 224-232, 1967.

VIEIRA, J. B. Uma avaliação das iniciativas (SOUZA, 2008; FILGUEIRAS, 2009) de combate à corrupção do Governo Federal no Brasil. Encontro de Administração Pública e Governança, 2., 2006, São Paulo. Anais... São Paulo: Anpad. 2006.

Temístocles Murilo Oliveira Júnior

Doutorando em Políticas Públicas, Estratégias e Desenvolvimento na Universidade Federal do Rio de Janeiro. Mestre em Administração pela Universidade Federal Fluminense. Auditor Federal de Finanças e Controle do Ministério da Transparência, Fiscalização e Controladoria-Geral da União-CGU, desde 2005.

Contato: temuju@gmail.com

Frederico José Lustosa da Costa

Doutor em Gestão, pelo Instituto Superior de Ciências do Trabalho e da Empresa (ISCTE/IUL), em Lisboa, Portugal, também reconhecido pela Universidade de Brasília (UnB) como Doutorado em Administração. É professor do Programa de Pós-graduação em Administração (PPGAd) da Universidade Federal Fluminense e membro da Academia Brasileira de Ciências da Administração.

Contato: fredlustosa@gmail.com

Arnaldo Paulo Mendes

Professor de Graduação e Pós-Graduação em Administração e Marketing da Universidade Estácio de Sá. Mestre em Administração pela Universidade Federal Fluminense.

Contato: apmendes279@gmail.com 
